International Journal of Instruction e-ISSN: 1308-1470 • www.e-iji.net
October $2020 \bullet$ Vol.13, No.4

p-ISSN: 1694-609X

pp. $849-866$

Received: 04/09/2019

Revision: 18/05/2020

Accepted: 09/06/2020

OnlineFirst:29/08/2020

\title{
Rhetorical Structure Variations in Literature Review Chapters of Applied Linguistics Master's Theses by Iraqi and International Students
}

\author{
Ahmed Rawdhan \\ Lecturer, University of Babylon, Iraq, ahmedrawdhan68@gmail.com \\ Saman Ebadi \\ Assoc. Prof., corresponding author, Razi University, Iran, samanebadi@yahoo.com \\ Nguyen Thi Thuy Loan \\ Lecturer, Faculty of Education and Educational Innovation, Kalasin University, \\ Thailand,thuyloancailay@yahoo.com
}

By employing Chen and Kuo's (2012) framework, this study comparatively investigated the rhetorical differences/similarities existing in the Literature Review chapters of Master of Arts (MA) theses authored by international and Iraqi MA students in the field of applied linguistics. The results showed that almost half of the international LR chapters had Introduction - Body - Conclusion progression, but this structure was rare in Iraqi ones. Move1 (Establishing one part of the territory) was conventional whereas Move 2 and Move 3 were both optional in the corpus. Analysis of steps showed that international students used the step of Related research reviewing more than Iraqi counterparts for the realization of Move 1. International students justified the significance of their study by the step of Gap indication whereas Iraqi students resorted to the step of Concluding one part of the research. Move 3 was commonly occurred by the use of Indicating research aims step in the two sets of LR chapters. Generally, the findings show that, in writing LR chapters, Iraqi MA students attempted to be familiar with their area of research interest rather than to cast their critical approaches to the current status of the established research in the literature. These findings call for a genrebased pedagogy in academic writing to sharpen the awareness of Iraqi MA students of the functions of each move and step in LR chapters in applied linguistics.

Keywords: rhetorical variations, moves/steps, theses, literature review, applied linguistic

\section{INTRODUCTION}

Literature Review (LR) plays a vital role in an academic activity. It is considered as an indispensable part of an academic genre, enabling the researchers to be aware of the

Citation: Rawdhan, A., Ebadi, S., \& Loan, N. T. T. (2020). Rhetorical Structure Variations in Literature Review Chapters of Applied Linguistics Master's Theses by Iraqi and International Students. International Journal of Instruction, 13(4), 849-866. https://doi.org/10.29333/iji.2020.13452a 
status of the current contributions undertaken by others (Boell \& Cecez-Kecmanovic, 2014). The main function of LR is to justify the value of the research, and to show why it is distinct from what is documented in the literature (Creswell, 2003; Rudestam \& Newton, 2001). This indispensable piece of information in LR chapter functions a solid foundation for their Master of Arts (MA) research project (Kaminstein, 2017). However, contextualizing the established knowledge, theories, approaches and previous works is usually a demanding performance, particularly for non-native MA students (Cooley \& Lewkowicz, 1997; Kwan, 2006; Shaw, 1991).

LR chapter plays an important role in an MA thesis as well. It provides background, support, and compelling evidence for the importance of the thesis. However, performing a thorough literature review is a notoriously challenging task. Generally, every MA thesis includes an LR chapter, which motivates the novice researchers to report, evaluate and synthesize earlier relevant publications in order to create the foundation for his/her thesis' contribution. In fact, this chapter could be considered as a basis for the choice of methodology, research design, and the interpretation of results presented in the study (Kaminstein, 2017; Khoo et al., 2011). Thus a well-crafted review literature does not end up just as a description of a series of studies (Cronin et al., 2008); however, it includes the writer's voice and stance, which guide the reader through the text by reporting what has been done previously and pointing at what still remains to be done (Gil-Salom \& Soler-Monreal, 2014).

The relevant literature shows that very few studies have reported the rhetorical behavior of graduate students throughout an applied linguistics' thesis (Bunton, 2002; Chen \& Kuo, 2012; Kwan, 2006; Nguyen \& Pramoolsook, 2014a). The current contextualized analyses investigate the rhetorical behaviors of native MA students; only one investigation (i.e., Nguyen \& Pramoolsook, 2014a) analysed the rhetorical behaviours of non-native MA students, and it concluded that the majority of students were not able to indicate the value of the reported studies in their LR chapters. The relevant literature also shows that research on different sections of Iraqi MA theses is limited to few recent studies, merely investigating the opening sections of an Iraqi MA thesis in applied linguistics (Abid Saleh, 2018; Al-Zubaidi, 2013; Ebadi et al., 2019).

In Iraq, 13 universities are permitted to offer Master of Arts (MA) programs in English for English teachers. The programs are mainly conducted by Iraqi professors whose doctoral degrees were obtained either in Iraq or abroad. Every year, about 25 new students are recruited for the programs by each university based on its selection criteria. These MA programs require their students to finish 28 units and a thesis for their graduation. It seems that there is no formal instruction or specific guideline for writing each chapter/section of an MA thesis in Iraqi universities, and the students arrange the style and content of each chapter of their thesis quite often based on theses written by previous students in their faculty libraries. Furthermore, in some informal conversations with some Iraqi graduate students, the researchers learned that some of the students consult with online resources in formatting their theses, which is rarely praised by their supervisors and the reviewers. 
The lack of a well-organized guideline or formal instruction in thesis writing could discourage Iraqi MA students in pursuing their academic goals in the field of applied linguistics as they move forward in their scientific careers. Despite its significance on equipping the Iraqi English teachers' with relevant professional and research skills, the relevant literature shows that research on different sections of Iraqi MA theses is quite in infancy limited to few recent studies, merely investigating the opening sections of Iraqi MA thesis in applied linguistics (e.g., Abid Saleh, 2018; Al-Zubaidi, 2013; Ebadi et al., 2019).

To the best of the researchers' knowledge, there is a paucity of research on examining the rhetorical behaviors of Iraqi graduate students in LR chapters of MA theses in the field of applied linguistics. Therefore, this study comparatively investigates the rhetorical differences/similarities existing in the LR chapters of MA theses written by Iraqi and international MA applied linguistics' students by answering the following research questions:

1- What are the move and step structures of LR sections of MA theses written by Iraqi applied linguistics' students?

2-What are the similarities and differences of moves and steps in LR chapters written by Iraqi and international MA students in applied linguistics?

\section{LITERATURE REVIEW}

\section{Move Analysis in Literature Review}

Reviewing the literature is a process through which the researchers "identify, analyze, assess, and synthesize earlier research" (Boell, Cecez-Kecmanovic, 2014, p. 258). It enables the researchers to evaluate the credit and value of the current investigation (Kwan, 2006). However, as the studies show, writing an appropriate LR is a challenging procedure for non-expert thesis writers.

In a preliminary study, Kwan (2006) analyzed the rhetorical structure of LR chapters in doctoral dissertations in applied linguistics. Kwan reported on the Introduction-BodyConclusion progression in the analyzed chapters. Move 1 (Establishing one part of the territory) and Move 2 (Creating a research niche) were the predominant moves in the corpus. Strategy 1A (Surveying the existing state of knowledge and non-research practices) was of the highest frequency for Move 1 configuration. Move 2 was predominantly realized by Counter-claiming. Step of Announcing the aim of the research was the frequent step of Move 3 (Occupying the research niche). None of the moves was obligatory.

Chen and Kuo (2012) examined the rhetorical structures of LR chapters in 20 MA written by international writers. The results showed that almost all of the chapters had an introductory move and the body part was divided into several thematic sections. The steps of Surveying the non-research-related phenomena and Surveying the researchrelated phenomena enjoyed the highest frequencies in Move 1 realization. Comparing with Kwan's model for LR chapter, Chen and Kuo identified and included a new step (i.e., Concluding a part of literature review and/or indicating transition to reviewing a 
different area) to the proposed framework. The main rhetorical function of this step was to represent the completeness of the review of a given theme (Nguyen \& Pramoolsook, 2014a).

In a recent study on the rhetorical structures of 30 low and high-rate LR chapters of MA theses written by Taiwanese students, Hsiao (2016) found that the topic in low-rate LRs was mainly initiated at the single move of knowledge presentation (Referring to introduction to theory, belief, practices or field knowledge), and there was little attempt to challenge the previous citations. Conversely, the high-rate LRs were characterized with multiple cycles of moves. That is, the writers dominantly used three-move configurations and 4-move configurations, in which the topic discussions were unanimously led to reach the final move (Announcing their focal studies). Furthermore, the high-rate RLs utilized information prominent citation as a key text feature to summarize the contents from multiple articles and analyze the viewpoints shared from them.

The rhetorical analysis of Nguyen and Pramoolsook (2014a) on the LR chapters in Vietnamese TESOL MA theses showed that Move 1 and Move 2 were conventional and Move 3 was optional. The researchers concluded that Vietnamese MA students merely displayed familiarity with their area of research interest without synthesizing the reviewed literature. These few studies show that MA students prefer to illustrate their familiarity with the established knowledge of their research domain (Petrić, 2007), and they are not adequately experienced to write good LR chapters since that are not probably familiar to the rhetorical structures in organizing the LR chapters in their theses

It is indicated in the literature that research on the overall structure of Iraqi MA thesis is limited to abstract and introduction sections (Al-Zubaidi, 2013; Jawad \&Abid Saleh, 2018; Ebadi et al. 2019). Therefore, this study investigates how Iraqi MA students organize the content of their LR chapters in achieving their communicative functions, and how it is similar to or different from those written by international students.

\section{METHOD}

\section{Corpus}

LR texts analyzed in this study were drawn from 60 MA theses in applied linguistics 30 Iraqi and 30 international MA theses written in English language. All theses were restricted to a period of five years (2012-2017). Iraqi theses were written by MA students in three Iraqi universities. The international MA theses were downloaded from ProQuest Thesis and Dissertation database. It is assumed that international writers generated their MA theses based on the same rhetorical norms similarly used by native English writers since international theses are usually supervised and/or evaluated by English-speaking academics (Soler-Monreal et al., 2011).

Iraqi MA theses were randomly obtained with the writer's consent from the libraries of all three universities offering MA programs. After permissions were obtained from the heads of the English Departments, the researchers gained access to Iraqi electronic 
theses. The international MA theses were retrieved from the ProQuest database. First, the researchers collected a pool of 100 MA theses in applied linguistics. Then, they utilized simple random sampling to select 30 required MA theses out of 100 instances to answer the research questions of the study. Similar to Nguyen and Pramoolsook (2014a) approach to creating corpus, the researchers randomly coded each chapter from number LR1 to LR30 for the ease of reference and the anonymity of thesis writers. Then, each chapter was copied and pasted onto a separate file and further-coded for the ease of the analysis of individual chapters.

\section{Procedure}

A functional-semantic approach was used to identify the move - step structures in the selected LR chapters. This approach calls for cognitive judgment, rather than a reliance on linguistic criteria, in identification of the intention of a text and the textual boundaries (Bhatia, 1993; Paltridge, 1994). Chen and Kuo's (2012) framework (Appendix A, Table 7) was used to classify moves and steps in Iraqi and international LR chapters. This model is a comprehensive scheme for analyzing the overall structure of MA theses in the field of applied linguistics (Nguyen \& Pramoolsook, 2014b).The criteria suggested by Kanoksilapatham (2005) were employed for the classification of moves and steps' frequencies in the selected LR chapters. Therefore, if a particular move or step occurs in every chapter $(100 \%)$, it is classified as obligatory. If a move or step is found below $60 \%$ in the corpus, it is regarded as optional and if the occurrence of a certain move or step ranges from $60-99 \%$, it is conventional.

Two inter-raters checked the reliability of the move-step identification in order to avoid the subjectivity in the identification procedure. The first rater was one of the same researchers currently being a $\mathrm{PhD}$ candidate in TEFL and the other rater was a university professor holding PhD in TEFL and specialized in corpus-based analysis. During the move identification process, which was performed separately, the researchers regularly held several discussion sessions to solve any possible problems in move and step categorization. Finally, we checked the results against each other yielding a rather high inter-rater reliability rate $(88 \%)$. After that, each chapter (in both corpora) was rigorously read and analyzed based on the Chen and Kuo's (2012) model. The frequencies of each move, step, and their sequences were recorded in each corpora. Then, the frequencies were compared in order to answer the research questions. Similar to Kwan (2006) approach to analyzing the content of each LR chapter, the researchers conducted a sectional analysis; that is, they divided each chapter into thematic units based on the sectional boundaries that were indicated by such meta-signals, such as section breaks, section headings, and their respective numbering systems. After that, Chen and Kuo's (2012) model was conducted on each thematic unit.

\section{FINDINGS AND DISCUSSION}

\section{Move Patterns}

Table 1 indicates the overall structures of LR chapters in international and Iraqi MA theses in applied linguistics. Table 1 shows that 28 international chapters have been separated from introduction chapters and only 2 LR chapters have been imbedded into 
introduction. However, all Iraqi researchers have organized this section as a separated chapter.

Table 1

Overall Structure of International and Iraqi LRc Chapters

\begin{tabular}{lll} 
& International Theses & Iraqi Theses \\
Number of Theses & 30 & 30 \\
Separate Chapters & 28 & 30 \\
Embedded Chapters & 02 & 00 \\
\hline
\end{tabular}

The presence of separate LR chapters was also reported in Kwan (2006), Chen and Kuo (2012), and Nguyen and Pramoolsook's (2014a) investigations. It seems that MA graduate students are required to contextualize the foundation of their MA thesis in a separate chapter not embed it in introduction chapter. It was found that many Iraqi students (86.6\%) preferred to embed an introductory text to the beginning of LR chapters (Table 2). The presence of this move was observed in 17 international LR chapters. Most of the Iraqi LR chapters had the heading of Introduction whereas only 4 (out of 17) international theses had this title at the beginning of their LR chapters. Kwan (2006) also reported the inclusion of introduction heading at the opening of PhD LR chapters (89.6\%) in her study. Kwan argued that the main function of the heading was probably to help the readers easily go through the long introductions in $\mathrm{PhD}$ dissertation. This issue seems to be verified by the Iraqi LR chapters too, since the main function of these small texts was to inform the readers of the themes discussed in the chapter in advance (Table 2). As Table 2 shows the strategy of Indicating the overall structure occurred more frequently than Providing background information step both in Iraqi and international LR chapters. This step was also common in Nguyen and Pramoolsook (2014a), in which Vietnamese MA students, in advance, informed "the reader of the purposes, structures, themes and justifications for the themes to be reviewed in the following sections" (p. 289).

Table 2

Frequency of Introductory and Concluding Texts in International and Iraqi LR Vhapters

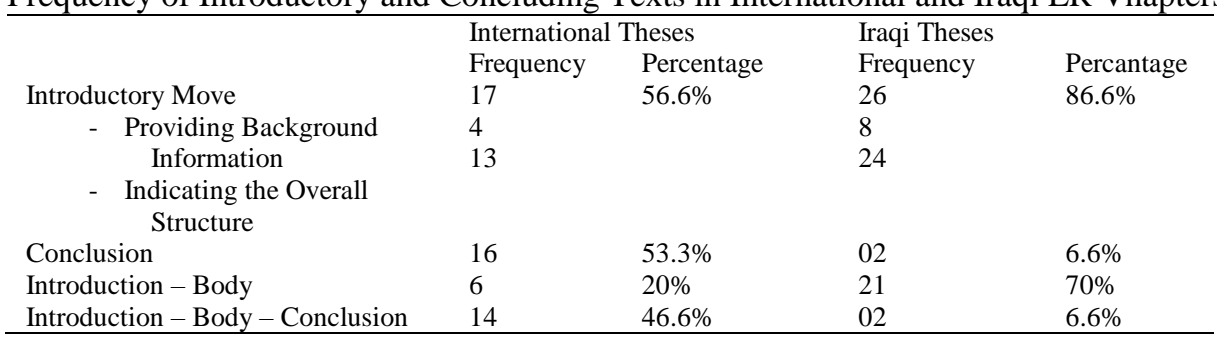

Table 2 further shows that although Iraqi MA students frequently embedded the introductions to the beginning of the LR chapters, international students preferred to include concluding texts to the end of their RL chapters. These concluding texts presented the gist or the themes reviewed in the LR chapters (Example 2). Some of these concluding texts contained Move 2 (Creating a research niche), and Move 3 (Occupying niche) as well. 


\section{Example 2}

Summary of the literature review

Writing is an important component of learning a second language. However, it poses many problems for learners because the ability to write in the new language depends on the knowledge of the language and skills in native language. Krashen (1985) warned that writing does not cause language acquisition and .... Wright (2010) provided a detailed account of the problems faced by English learners when writing in English, and explained how .... Kim (2005) reported on how journal writing helped ... Pappamihie et al. (2008) investigated if .... The results showed that native language was not always helpful when brainstorming. The following study was conducted in an effort to .... This study looks at an activity that incorporates fun and some often criticized teaching strategies, rote learning and memorization, and determine its usefulness in reducing anxiety in order to help adult English learners produce both oral and written output [Move 3: Restating the purpose of study].(International LR Chapter, T 11)

Writing a reviewing chapter is daunting task and the graduate students usually immerse themselves to the topic nad they practice maximum efforts to integrate their studies to the established knowledge. It seems that the main function of these short concluding texts is to enable students not to be submerged excessively to the topic. Therefore, in order to avoid this issue, the international students restated the main discussed themes, contextualized the most convincing argument, mentioned the current status of the research and restated the purposes of their research projects. The international MA students might have felt that restating these pieces of information not only could help them to emphasize on the main points, but also it might impress the readers or the committee to cast a positive approach on the novice researchers in that he/she was adequately familiar to the area and the status of the undertaken research.

Table 2 also illustrates that almost half of the international MA students considered LR chapters as an essay since they followed an Introduction - Body - Conclusion structure in arrangement of its content and style. In other words, wherever an international student started the chapter with an introduction move, he/she closed the chapter with a concluding text. However, in Iraqi theses, only two LR chapters were featured with Introduction - Body - Conclusion progression. This rhetorical behavior on behalf of international students is probably due to the formal instructions to which they have been exposed to, either during high school or during university (MA program) writing courses.

\section{Thematic Units in the Body Texts}

Our analysis identified 196 thematic units in the body sections of international LR chapters, and 366 instances in Iraqi corpus. Table 3 shows that Move1 (Establishing one part of the territory) was conventional both in international (88.7\%) and Iraqi (91.5\%) LR chapters. This move was also conventional in Kwan's (2006) and Nguyen and Pramoolsook's (2014a) analyses. The frequent use of this strategy in our corpus supports the argument that MA students try to show their familiarity with the topic and the knowledge of their disciplines (Nguyen \& Pramoolsook, 2014a). 
Table 3

Frequency Counts of Thematic Units in the Body of LR Chapters Theses

\begin{tabular}{|c|c|c|c|c|}
\hline \multirow{2}{*}{\multicolumn{2}{|c|}{ Thematic Units }} & \multirow{2}{*}{$\begin{array}{l}\text { International Theses } \\
196\end{array}$} & \multicolumn{2}{|l|}{ Iraqi Theses } \\
\hline & & & 366 & \\
\hline & $\begin{array}{l}\text { Number of Units } \\
\text { with the Moves }\end{array}$ & Individual Counts & $\begin{array}{l}\text { Number of Units } \\
\text { with the Moves }\end{array}$ & Individual Counts \\
\hline M1 & $174(88.7 \%)$ & 278 & $335(91.5 \%)$ & 514 \\
\hline M2 & $62(31.7 \%)$ & 89 & $36(9.8 \%)$ & 30 \\
\hline M3 & $28(14.2 \%)$ & 32 & $10(2.8 \%)$ & 12 \\
\hline
\end{tabular}

Table 3 indicates that Move 2 (Creating a research niche) was found optional in Iraqi corpus whereas this rhetorical structure was conventional in some previous studies (Chen \& Kuo, 2012; Kwan, 2006; Nguyen \& Pramoolsook, 2014a). Iraqi students even utilized this move far less frequently than their international counterparts $(9.8 \%$ vs. $37.1 \%$ ). The conventional use of Move 1 and the low occurrence of Move 2 in Iraqi LR chapters indicate that Iraqi students tended to summarize the previous research, and they did not prefer to cast their critical thinking and integrate the topic into the literature. This finding shows that the current Iraqi MA programs might not be qualified enough to help Iraqi MA students reflect their critical thinking or their analytical ability in showing the drawbacks in the literature and the significance of their area of research interests. Hence this program is required to be updated based on MA students' needs. Similar to some previous studies on LR chapters (Chen \& Kuo, 2012; Kwan, 2006; Nguyen \& Pramoolsook, 2014a), this research found that Move 3 is optional in both Iraqi and international theses (Table 3). The low occurrence of Move 3 tends to show that this rhetorical structure is not preferred by these thesis writers. This is probably due to the fact that most of Move 3 steps are realized in the introductory chapters, through which the writers report on the research aims, significance, hypotheses, structure and design. Therefore, they might have not considered it appropriate to contextualize these rhetorical features in the LR chapters. This study also investigated the move configuration in Iraqi and international LR chapters through which some various schematic patterns were observed in the analyzed corpus. Figure 1 shows that international writers utilized the regular M1-M2 pattern $(20.5 \%)$ five times higher than those in Iraqi (5\%) LR chapters. The irregular form of this pattern was also observed in higher percentages in international than Iraqi ones (17.38\% \& $1.6 \%$, respectively).

The rest of the patterns, including M1 - M3, M1 - M2 - M3, and their irregular forms were occurred with a low frequency in the corpus. However, figure 1 shows that whereas the occurrence of Move 1 was considerably in high percentages, the presence of M2 and M3 were in low frequencies. It is implied from these rhetorical behaviors that both international and Iraqi MA students had a high tendency to neutrally contextualize the relevant approaches, theories and linearly describe the conducted researches without casting a critical approach to the themes of the previous relevant works. In fact, few of them justified the integration of their research into the cited references. These findings show that the majority of MA students have the anxiety of covering the area of their research focus thoroughly rather than the tendency to writing an integrative and critical literature review chapter. 
According to these move-step sequences, generally, it seems that the move-step structure is more sophisticated in international LR chapters than Iraqi ones since the identified thematic units were characterized with many recursive structures in international chapters. The presence of these non-linear structures in international LR chapters is probably due to the formal instruction or guidelines to which international students might have been exposed in organizing the contents and styles of their LR chapters.

\section{Step Patterns}

\section{Steps in move 1 (establishing one part of the territory of one's own research)}

Table 4 represents the frequency counts of Move 1 steps observed in all thematic units on which Chen and Kuo's (2012) model was conducted. According to Table 4, Nonrelated research reviewing (1A) step was conventional both in international and Iraqi chapters $(65.8 \% \& 62.5 \%$, respectively). This step was also frequent in some similar analyses (Chen \& Kuo, 2012; Kwan, 2006; Nguyen \& Pramoolsook, 2014a). The frequent occurrence of this step verifies our argument that these two groups of MA students attempted to show the committee members their familiarity with the domain of their research or more specifically generalize the topic under investigation. Because, as Kwan (2006) maintains, the main proposition of this step is to objectively report and explain the terminology, constructs, theories, and the characterization of phenomena which are associated with the topic.

Similar to Vietnamese MA students (Nguyen \& Pramoolsook, 2014a), Claiming centrality $(1 B)$ was optional in our corpus, and it was realized in small percentages of occurrences $(5.8 \% \& 2.8 \%$, respectively). The low occurrences of $1 B$ step shows that international and Iraqi MA students were not adequately experienced to specify whether it was the need for research in the real world (phenomenal world) that led them to perform research or it was due to the existing gaps in the research (epistemic world) which motivated them to perform their research projects. Generally, the low occurrence of the Claiming centrality step in LR chapters of MA theses could be due to the reason that MA students might have felt less confident to propel the members of their discourse community "to accept that ... [their] research is part of a lively, significant or wellestablished research area" (Swales, 1990, p. 144).

Table 4

Frequency Counts of Steps in Move 1 (establishing one part of the territory)

\begin{tabular}{|c|c|c|c|c|}
\hline & \multicolumn{2}{|c|}{ International Theses } & \multicolumn{2}{|c|}{ Iraqi Theses } \\
\hline Total Counts o Move 1 & 278 & & 514 & \\
\hline \multicolumn{5}{|c|}{ Number of Instances of Steps within M1 } \\
\hline Non-related Research Reviewing (1A) & 183 & $65.8 \%$ & 321 & $62.5 \%$ \\
\hline Centrality Claiming (1B) & 16 & $5.8 \%$ & 13 & $2.5 \%$ \\
\hline Research-related Reviewing (1C) & 103 & $37 \%$ & 36 & $7 \%$ \\
\hline
\end{tabular}

Similar to previous works (Kwan, 2006; Nguyen \&Pramoolsook, 2014a), Researchrelated reviewing (1C) was also optional in both international and Iraqi LR chapters ( $37 \%$ \& $7 \%$, respectively). This finding indicates that MA students in applied linguistics show preferences to establish the territory of their research interests (Move 1) through 
defining or explaining the terminologies, theories, the beliefs and characterizations of non-research practices (1A) rather than highlighting the importance of their topics (1B) or reviewing the subjects, procedures, and the results of previous studies (1C). They might have found this way of territory establishment far easier than reviewing previous citations or claiming the significance of their studies.

Figure 2 indicates the presence of steps and their combinations in Move 1. According to figure 2, Iraqi MA students used step1A two times higher than their international counterparts. By contrast, international students utilized step $1 \mathrm{C}$ more than Iraqi students.

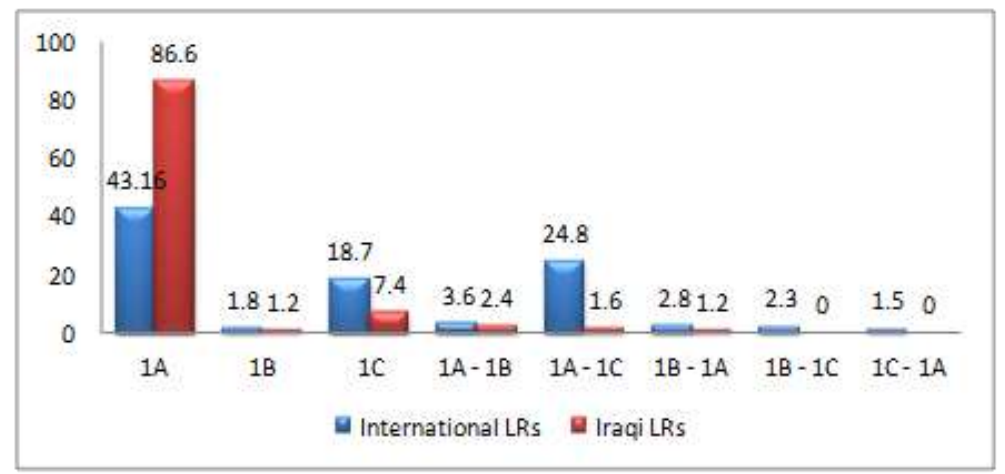

Figure 1

Distribution of Move 1 (Establishing one part of the territory) Configurations

Figure 1 also shows that the step pattern of $1 \mathrm{~A}-1 \mathrm{C}$ was found to be more frequent in international than in Iraqi LR chapters. The frequent application of this step pattern made the realization of Move 1 in international corpus more sophisticated and recursive than Iraqi ones. The low occurrence of 1A - 1C step sequence in Iraqi corpus shows that reviewing the previous research-related knowledge was not of favorite for the most majority of Iraqi MA students. Instead, they tried to describe the theories or approaches on which their studies were grounded. Our hypothesis is that a low preference to review the related studies might not be of considerable help for Iraqi students in identifying the possible existed flaws in the related citations literature. In simple words, Iraqi students may not be able to cast a critical approach to the literature in order to justify the significance of their studies.

\section{Steps in Move 2 (Creating a Research Niche)}

Table 5 shows the frequency counts of Move 2 steps realized in the analyzed corpora. We found 80 and 29 instances of Move 2 in international and Iraqi LR chapters, respectively. It should be mentioned that four international and eleven Iraqi LR chapters did not have any Move 2 instances. More than half of international MA students $(60 \%)$ utilized Gap indicating step ( $2 A)$ for Move 2 realization whereas Iraqi counterparts used almost one third of this step $(37.9 \%)$ in their LR chapters. The frequent interests of international students in the use of this step is probably due to the reason that they 
might have felt that this rhetorical option is the easiest and most straightforward manner to establish the niche in previous investigations. This step was commonly occurred in one or two sentences long, usually preceded by the step of Related-research reviewing (1C). That is, these graduate students, first, reported the relevant works (1C), and as they felt it was adequate to make reference to previous citations, they immediately resorted to Gap indicating step by shifting their tone of voice from a neutral description to a critical announcement of their works.

Table 5

Frequency Counts of Steps in Move 2 (creating a research niche)

\begin{tabular}{lllll}
\hline & International Theses & \multicolumn{2}{c}{ Iraqi Theses } \\
Total counts of Move 2 & 80 & $15 \%$ & 29 & $13.8 \%$ \\
Counter claiming (2A) & 12 & $60 \%$ & 11 & $37.9 \%$ \\
Gap-indicating (2B) & 48 & $6.5 \%$ & 00 & 00 \\
Asserting confirmative claims (2C) & 5 & 00 & 00 & 00 \\
Asserting the relevancy (2D) & 00 & $8.7 \%$ & 1 & $3.4 \%$ \\
Establishing theoretical positions (2E) & 7 & $18.75 \%$ & 13 & $44.8 \%$ \\
Concluding a part of literature (2F) & 15 & \\
\hline
\end{tabular}

Table 5 further indicates that, unlike international students, Iraqi MA students showed a rather high tendency to the use of Concluding a part of literature $(2 F)$ step to justify the significance of their studies. In Iraqi corpus, all of Concluding a part of literature $(2 F)$ steps were preceded by the Non-research related knowledge (1C) step (Example 3):

\section{Example 3}

Definitions and characteristics (speech act of refusal)

Refusal is a speech act which .... Refusing means... This speech act belongs to a family of verbal responses which .... Searle and Vandervken (1985: 195) define the speech act of refusal .... Chen and Zhang (1995: 121) define refusal as .... Holmes et al. (2004: 948) define refusal as ... From a sociolinguistic viewpoint, refusal is.[Surveying Nonresearch related knowledge step].Refusals have been one of the most studied topics in pragmatics [Claiming centrality of topic].... Refusal can be defined as an attempt ... A more comprehensive definition of refusal is offered by Gass and Houck (1990: 2) as .... Refusals are known as a sticking point in cross cultural communication, (Kwon, 2004: 340). He makes the point that "refusals ... Making a refusal in one's native language can be awkward ... Refusals can be characterized as ... [Surveying Non-research related knowledge step]. In sum, refusal is a complex speech act that requires not only negotiation of a satisfactory outcome, but also "face- saving maneuvers" to accommodate the non-compliant nature of the act (Gass and Houck, 1990: 2) [Concluding one part of literature step].

Types of refusal

Refusals are found in four types of exchanges, namely, ...”(Iraqi LR Chapter, T 26)

Example 4 shows the rhetorical behavior of one Iraqi MA student in the development of a thematic unit entitled as "2.2.1 Definitions and Characteristics". As the example shows, he/she,first, elaborated on the topic (speech act of refusal) in details, including its 
definitions and characteristics, and, then drew a general theme as a sign of transition to the next thematic unit (i.e., 2.2.2 Types of Refusal) presenting information on different types of refusal speech act. In international LR chapters, however, the step of Concluding one part of literature $(I F)$ was usually preceded by reviewing the Researchrelated Knowledge (1A) step rather than surveying the Non-research related knowledge strategy (Example 4).

\section{Example 4}

"Computer-assisted language earning in ESL

Some studies have examined the use of CALL in ESL; ... For instance, Kramsch and Anderson (1999) observed that CALL in ESL .... .... ... Studies such as Armstrong \&Yetter-Vassot (1994) and Warschauer (2003) reveal how the integration of CALL ... ... For instance, Jackson (2008), Education Week (2007), McCampbell (2002), and Marshall (2002) acknowledge that ... [SurveyingResearch-related knowledge step]. Overall, research in CALL in ESL shows that there are positive results of adopting technology to support language learning and a lot of studies associate the positive results with learners' increased motivation and participation (Hirvela, 2005; Warschauer, 2003) [Concluding one part of literature step]"(International LR Chapter, T10)

As Example 4 indicates, in this thematic unit, an international MA student, first, reviewed some relevant studies examining the use of CALL in ESL contexts, and then s/he concluded or drew the general theme of the thematic unit (i.e., the positive effect of CALL in ESL situation).

Table 5 further shows that the step of Counter-claiming occurred almost with similar frequencies in both international and Iraqi LR chapters $(13.75 \%$ \& $10.34 \%$, respectively). Counter-claiming step also occurred with low percentages in Vietnamese and native English LR chapters (Chen \& Kuo, 2012: Nguyen \& Pramoolsook, 2014a, respectively). However, this strategy was reported conventional in Kwan's (2006) analysis on PhD LR chapters. Nguyen and Pramoolsook (2014a) argued that the conventional use of Counter-claiming step in $\mathrm{PhD}$ LR chapters indicates that $\mathrm{PhD}$ programs "require students to demonstrate not only their critical thinking, but also their ability to identify the flaws in the existing knowledge in their field in order to establish the novelty of their works" (p. 294) while MA programs expect students to reflect their familiarity with their area of focus. Hence, like Nguyen and Pramoolsook, we hypothesize that Iraqi and international students have a higher tendency to reflect their familiarity with the knowledge in their area of research rather than to convince niche needs to be built by evaluating and rejecting the previous related work. Perhaps, these MA students have not been adequately exposed to formal instruction on how to be function effectively in evaluating, criticizing, and even rejecting the literature.

Table 5 also shows that international and Iraqi student utilized affirmative strategies in low percentages in LR chapters. Affirmative strategies "are elements that writers use to show their acceptance of the citations that are provided in Move 1" (Kwan, 2006, p. 45). These strategies are classified as (a) Asserting confirmative claims (2C), (b) Asserting 
the relevancy (2D), and (c) Establishing theoretical positions(2E) (Kwan, 2006). Asserting the relevancy step was absent in our corpus.

In general, the results show that both international and Iraqi MA students prefer to establish the niche by negational strategies (i.e., Counter-claiming and Gap indicating steps) rather than affirmative strategies. These findings are in line with Kwan's (2006) and Nguyen and Pramoolsook's (2014a) analyses in which the affirmative steps were optional in the examined LR chapters. The low preferences of affirmative strategies in our corpus could be due to the nature of the field of applied linguistics itself. In details, these graduate students might have felt that since the field deals with human beings, the majority of established knowledge is context-specific, and, thereby not generalizable. In other words, probably, these graduate students did not (or even were not able to) affirm the established literature relevant to their work. Furthermore, these novice students might have not been adequately experienced to use these affirmative strategies, possibly due to lack of formal instructions.

Figure 2 shows the distribution of Move 2 configuration in international and Iraqi LR chapters. Figure 3 illustrates that the realization of Move 2 is not complicated both in international and Iraqi LR chapters, and the majority of these two sets of MA students resorted to a single step in Move 2 accomplishment. Only a very limited number of international students preferred to use step combination to signify the importance of their studies in LR chapters.

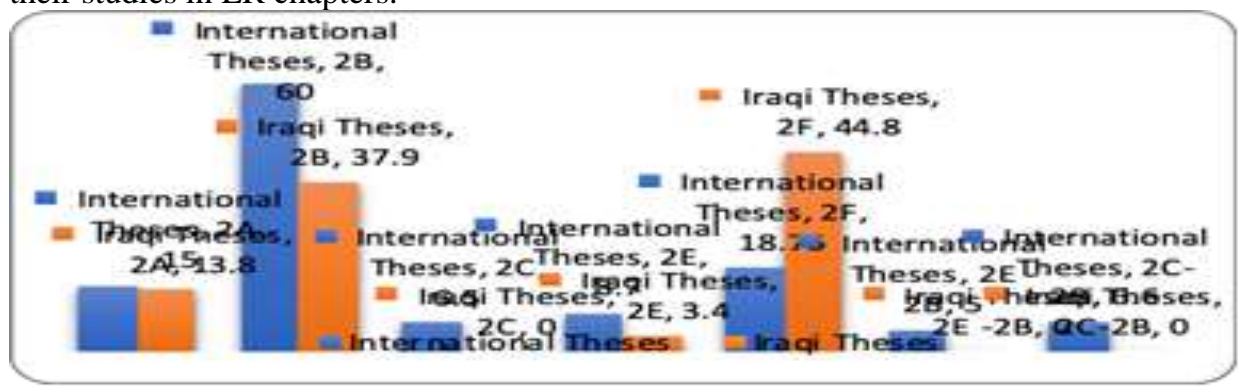

Figure 2

Distribution of Move 1 (Establishing one part of the territory) Configurations

According to Figure 3, the rhetorical behaviour of both international and Iraqi students were not complicated with respect to the realization of Move 2 in LR chapters. One might hypothesize that these novice writers were not probably familiar with the function of Move 2 in this significant chapters since the majority of them utilized negational strategies rather than affirmative ones (Table 5) in synthesizing and integrating their research projects to the body of the established knowledge in their area of interest.

\section{Steps in Move 3 (Occupying the Niche)}

Table 6 illustrates the frequency counts of Move 3 steps both in international and Iraqi LR chapters. Similar to the relevant works (Chen \& Kuo, 2012; Kwan, 2006; Nguyen \& Pramoolsook, 2014a), international and Iraqi MA students used the step of Indicating 
research aims, focuses, questions or hypotheses $(3 A)$ with high frequencies $(57.7 \%$ \& $60 \%$, respectively).

Table 6

Frequency Counts of Steps in Move 3 (occupying the niche)

Total Counts of Move 3 International Theses

Research aims, focuses, questions or hypotheses (3A)

Research design/process (3B) 45 Iraqi Theses 15

Indicating study significance (3C)

$\begin{array}{llll}26 & 57.7 \% & 9 & 60 \%\end{array}$

$\begin{array}{llll}9 & 20 \% & 6 & 40 \%\end{array}$

Table 6 indicates that Iraqi MA students $(40 \%)$ preferred to announce their research design two times higher than international students. Also, Table 6 shows that few international MA students explicitly announced the significance of their studies in LR chapter although they purported the contributions of their studies in the opening chapters. This step was absent in Iraqi LR chapters. The low occurrences of Move 3 along with its constituent steps could be due to this reason that these rhetorical structures are usually realized in the introduction chapters of the MA theses. It is in the introduction chapters that the MA students have probably considered appropriate to write about purpose/hypothesis, the thesis structure, its contribution, limitation and whatsoever relevant to their MA thesis projects.

Figure 3 illustrates the configuration of Move 3 in LR chapters of MA theses authored by international and Iraqi students. According to the figure, Move 3 was frequently realized by separate steps. The figure also shows that a very limited numbers of international students utilized step sequences for Move 3 configuration. These compound strategies were not observed in Iraqi LR chapters.

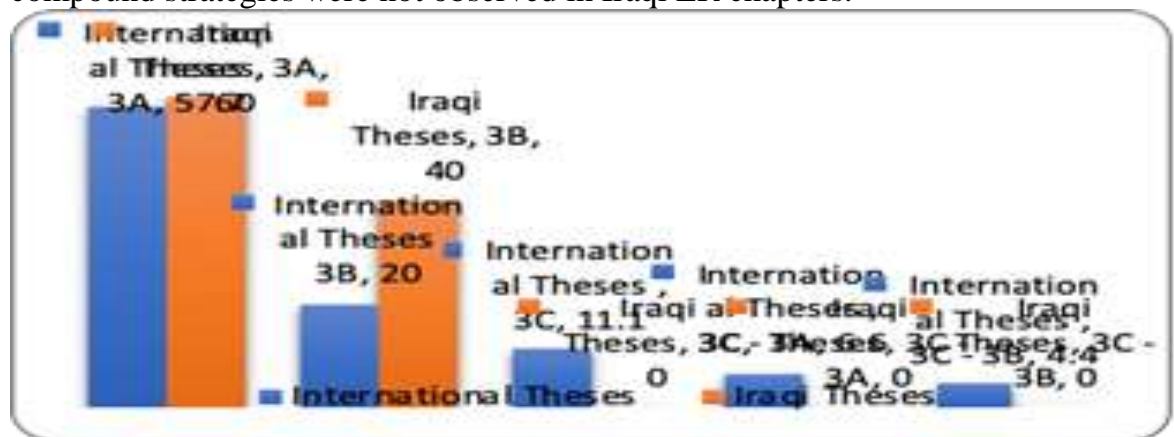

Figure 3

Distribution of Move 3 (Occupying the niche) Configurations

Similar to Move 2 accomplishment, it seems that the realization of Move 3 was not complicated in these two sets of LR chapters. Students merely announced the purpose of their research explicitly. This step commonly occurred at the ending sections of the LR chapters such as concluding text, where the researcher probably felt a sense of 
completeness and closure to reviewing literature. In other words, the frequent use of this step indicates that, perhaps, it is through this step that the novice researchers decided to signify the termination of review task and transition to the next chapters as explicitly instantiated in some conclusion/summery sections of the corpus (Example 8).

\section{Example 8}

In conclusion, this chapter looked at the literature related the copula omission by English learners and discussed the problem and reasons .... Moreover, it also provided a detailed discussion about .... Additionally, this chapter gave contrastive analysis .... Furthermore, it presented various studies that have been conducted on the omission of copula [Summary of the discussed themes]. This research is different from other researches in a way it contains both descriptive and inferential data. Moreover, the study examined ESL Saudi learners of English in Saudi Arabia while Al-Zahraniss study (1993) was conducted on Arabic speakers learning English in the United States. Furthermore, this study examines the negative and positive transfer from Arabic to English as well as to a comparison between the two languages structures [Move 3: Indicating the purposes of the study]. The next chapter, chapter III, will discuss the research methods of this thesis [Introducing the theme of the next chapter]. (International LR Chapter, T3)

\section{CONCLUSIONS}

This study examined the rhetorical structure of LR chapters in MA theses written by Iraqi and international MA students in the field of applied linguistics. The analysis showed that whereas the majority of international students ended LR chapters with concluding texts, Iraqi students primarily started their chapters with introductory texts. Almost half of international LR chapters followed Introduction - Body - Conclusion progression, but this structure was rare in Iraqi LR chapters. The occurrence of Move 1 was conventional both in international and Iraqi LR chapters. Move 2 and 3 were optional in the corpus. With respect to the use of steps in each move, it was found that Move 1 was commonly realized by two steps, namely, Non-related research reviewing $(1 \mathrm{~A})$ and Related research reviewing $(1 B)$. The former step was preferred with similar frequencies in the corpus, but international students resorted to the latter five times more than Iraqi counterparts (Table, 4). Move 2 was accomplished with two steps, including (a) Gap Indicating and (b)Concluding a part of literature. International students showed interest to justify the significance of their study by gap indication whereas Iraqi students showed favorite to conclude one part of their research. Move 3 was commonly occurred by the use of Indicating research Aims step in the corpus.

These findings show that Iraqi MA students have not been able to establish a solid foundation for their theses' contribution. One serious problem is that, unlike their international counterparts, they did not review the previous relevant works adequately despite their frequent references to the theories, knowledge and approaches in their area of research interests. It seems that the low occurrence of Move 2 instances in Iraqi LR chapters is probably due to the students' low preferences to review the related works. If the students examined the procedures, designs, participants, and etc. of the established 
studies, they could have functioned well in evaluating, synthesizing criticizing, and even rejecting the literature in LR chapters. The rare occurrences of Move 2 in Iraqi corpus shows that Iraqi students are not critical thinkers on the relevant literature. Therefore, effort should be practiced to develop this valuable ability in Iraqi EFL community so that these graduate students could be able to have a thorough understanding of their research interests. Critical thinking is an essential ability that the Iraqi MA students should learn "to note strengths, limitations, missing links, and/or logical inconsistencies in the arguments of the authors ... [they] are reading" (Kaminstein, 2017, p. 2). In order to make Iraqi MA students considerably critical thinkers, Iraqi professors could guide them to find the primary research sources. It is really important that the MA students rely on the first hand discoveries in their area of research (Kaminstein, 2017). Furthermore, the Iraqi supervisors could provide or at least help their MA students to search for literature review papers or meta-analysis or research articles. These sorts of articles could provide Iraqi MA students with "an overview of the research in the graduate students' area of interest, and they often highlight recent findings and gaps in the literature" (Kaminstein, 2017, p. 2).

The findings also call for genre-based pedagogy to teaching writing since this approach enables the teachers to explicitly introduce the external factors influencing and shaping the ultimate writing (Hyland, 2003). The findings of this study could be used to teach the Iraqi EFL students of how to write a well-crafted literature chapter in MA theses of applied linguistics. More specifically, Iraqi academic instructors should explicitly teach the functions of each move and step in literature chapters.

The caution should be practiced in generalizing the findings of this study since these results have not been evaluated validated with students and supervisors, as the main insiders. Hence, the future studies could improve this gap by consulting their findings with MA students and their supervisor in developing the LR chapters. This study analyzed the rhetorical structures of LR chapters in the MA theses authored by Iraqi graduate students in the field of applied linguistics. The future studies could describe the existing rhetorical organization in the other chapters (such as, Method, Results, Discussion, and Conclusion chapters) of Iraqi MA theses.

\section{REFERENCES}

Al-Zubaidi, A. G. (2013). Analyzing the rhetorical structure of linguistics dissertation abstracts written by Iraqi EFL Graduates. Journal of the College of Education for Human Sciences-Ibn Rushd-University of Baghdad, 204(2), 1-32.

Bhatia, V. K. (1993). Analyzing genre: Language use in professional settings. London: Longman.

Boell, S. K., \& Cecez-Kecmanovic, D. (2014). A hermeneutic approach for conducting literature reviews and literature searches. Comm. of the Asso. for Inf. Sys., 34, 257- 286.

Bunton, D. (2002). Generic moves in Ph.D. thesis introductions. In J. Flowerdew (Ed.), Academic discourse (pp. 57-75). London: Pearson Education.

Chen, T. Y., \& Kuo, C. H. (2012). A genre-based analysis of the information structure of master's theses in applied linguistics. The Asian ESP Journal, 8(1), 24 -52. 
Cooley, L., \& Lewkowicz, J. (1997). The writing needs of graduate students at the university of Hong Kong: A project report. Hong Kong Papers in Linguistics and Language Teaching, 18, 121-123.

Creswell, J. W. (2003). Research design: Qualitative, quantitative, and mixed methods approaches. Thousand Oaks, US: Sage Publications.

Cronin, P., Ryan, R., \& Coughlan, M. (2008). Undertaking a literature review: A stepby-step approach. British Journal of Nursing, 17(1), 38-43.

Ebadi, S., Rawdhan, A., S., Nguyen, T. T. L. \& Weisi, H. (2019). Rhetorical structure variations in abstracts and introductions of applied linguistics master's theses by Iraqi and international students. Iranian J. of Language Teaching Research, 7(1), $101-117$.

Gil-Salom, L., \& Soler-Monreal, C. (2014). Writers' positioning in literature reviews in English and Spanish computing doctoral theses. J. of Eng. for Acad. Purp., 16, 23 - 39.

Hsiao, C. (2016). Genre analysis of low-rated and high-rated literature reviews by EFL postgraduates. International Journal of English Language Teaching, 3(1), 1 - 19.

Hyland, K. (2003). Genre-based pedagogies: A social response to process. Journal of Second Language Writing, 12, 17- 29.

Jawad, F. A., \& Abid Saleh, A. K. (2018), Genre analysis of MA thesis abstracts by native and Iraqi non-native speakers of English. J. of Babylon University, 26, 37 - 50.

Kanoksilapatham, B. (2005). Rhetorical structure of biochemistry research articles. English for Specific Purposes, 24, $269-292$.

Kaminstein, K. (2017). Writing a literature review for an applied master's degree. Retrieved from: https://repository.upenn.edu/od_working_papers/23/.

Khoo, C. S. G., Na, J. C., \& Jaidka, K. (2011). Analysis of the macro-level discourse structure of literature reviews. Online Information Review, 35(2), 255 - 271.

Kwan, B. S. C. (2006). The schematic structure of literature reviews in doctoral theses of applied linguistics. English for Specific Purposes, 25(1), 30 - 55.

Nguyen, T. T. L., \& Pramoolsook, I. (2014a). Move-based structure of the master's thesis literature review chapters by Vietnamese TESOL postgraduates. LangLit, 1(2), 282-301.

Nguyen, T. T. L., \& Pramoolsook, I. (2014b). Rhetorical structure of introduction chapters written by novice Vietnamese TESOL postgraduates. $3 \mathrm{~L}$; Language, Linguistics and Literature, The Southeast Asian J. of Eng. Language Stu., 20(1), 61-74.

Paltridge, B. (1994). Genre analysis and the identification of textual boundaries. Applied Linguistics, 15(3), 288-299.

Petrić, B. (2007). Rhetorical functions of citations in high - and low-rated master's theses. Journal of English for Academic Purposes, 6(3), 238-253.

Rudestam, K. E., \& Newton, R. R. (2001). Surviving your dissertation: A comprehensive guide to content and process. Thousand Oaks, CA: Sage Publications.

Shaw, P. (1991). Science research students' composing processes. English for Specific Purposes, 10(3), 189 - 206. 
Swales, J. (1990). Genre analysis. English in academic and research settings. Cambridge: Cambridge University Press.

\section{Appendix A}

TABLE 7. Chen and Kuo's (2012) framework for the analysis of LR chapters of MA theses in applied linguistics

Introduction Indicating organization of the review chapter(s) and justifying the themes (areas) to be reviewed

Move 1: Establishing one part of the territory of one's own research by

Surveying the non-research-related phenomena or knowledge claims

Claiming centrality

Surveying the research-related phenomena

Move 2: Creating a research niche by

Counter-claiming (weaknesses and problems)

Gap-indicating (paucity or scarcity)

Asserting confirmative claims about knowledge or research practices surveyed

Asserting the relevancy of the surveyed claims to one's own research

Abstracting or synthesizing knowledge claims to establish a theoretical position or a theoretical framework

Concluding a part of literature review and/or indicating transition to review of a different area

Move 3: Occupying the Research Niche by

Indicating research aims, focuses, research questions or hypotheses

Indicating theoretical positions theoretical frameworks

Indicating research design/ processes

Interpreting terminology used in the thesis

Move 4: Establishing Data Analysis Procedures

Relating or recounting data analysis procedures

Justifying data analysis procedures

Previewing results

Referring to other studies

Providing background information

Providing support and justification

Providing definition of terms

Conclusion Providing a summary of the review of the themes and relating the review to the present study 